\title{
PENERAPAN METODE PERMAINAN DADU EJAAN UNTUK MENINGKATKAN KETERAMPILAN MENULIS KARANGAN SEDERHANA BAGI SISWA KELAS 2 SEMESTER II SDN MOJOLANGU 3 KOTA MALANG TAHUN 2012-2013
}

\author{
Ari Veronika \\ Sekolah Dasar Negeri Mojolangu 3 Kecamatan Lowokwaru Kota Malang \\ e-mail: sdnmojolanguiii@gmail.com
}

\begin{abstract}
Abstrak : Kemampuan menulis tidak dapat diperoleh secara alamiah, tetapi melalui proses belajar mengajar. Menulis merupakan kegiatan yang sifatnya berkelanjutan sehingga pembelajarannya pun perlu dilakukan secara berkesinambungan sejak Sekolah Dasar. Ketika anak meninggalkan dunia egosentris pada tahap operasi konkret, mereka mulai mengetahui bahwa beberapa benda dapat dikenali sedang lainnya tidak. Anak-anak kelas dua jarang menghawatirkan tulisan mereka, sebab mereka memberikan semua perhatian untuk menikmati aktivitas menulis dan bukannya mencari reaksi pembaca atau kesalahan ejaan. Penelitian yang digunakan adalah penelitian tindakan kelas, adapun subyek penelitian ini adalah siswa kelas II di SDN Mojolangu 3 yang terdiri dari 41 siswa. Respon siswa terhadap metode permainan dadu ejaan sangat baik, siswa merasa senang dan bersemangat apabila dalam proses belajar bahasa Indonesia menggunakan permainan dadu ejaan. Pembelajaran menggunakan metode permainan dadu ejaan dapat dijadikan alternatif bagi guru untuk diterapkan dalam pembelajaran bahasa Indonesia di kelas karena dapat memotivasi siswa untuk lebih aktif dan kreatif dalam belajar bahasa Indonesia terutama pada materi menulis karangan sederhana, slogan dan poster.
\end{abstract}

Kata Kunci: Media Dadu Ejaan, Ketrampilan Menulis.

\section{PENDAHULUAN}

Kemampuan menulis tidak dapat diperoleh secara alamiah, tetapi melalui proses belajar mengajar. Menulis merupakan kegiatan yang sifatnya berkelanjutan sehingga pembelajarannya pun perlu dilakukan secara berkesinambungan sejak sekolah dasar. Hal ini didasarkan pada pemikiran bahwa menulis merupakan kemampuan dasar sebagai bekal belajar menulis di jenjang berikutnya. Oleh karena itu, pembelajaran menulis di sekolah dasar perlu mendapat perhatian yang optimal sehingga dapat memenuhi target kemampuan menulis yang diharapkan.

Beberapa anak kelas dua melanjutkan kegiatan menulis dengan meyakinkan dan antusias seperti yang dikerjakan di kelas satu. Mereka menghasilkan sebuah cerita yang menjelaskan kehidupan mereka. Bagi anak-anak lain, menulis merupakan aktivitas yang tidak menarik. Kesalahan ejaan pada satu kata dapat menyebabkan siswa melemparkan kertas itu sebelum mencoba menulis lagi. Bahkan tanda salah yang kecil pun dapat menyebabkan anak membuang kertas dan memulai lagi.

Ketika anak meninggalkan dunia egosentris pada tahap operasi konkret, mereka mulai mengetahui bahwa beberapa benda dapat dikenali sedang lainnya tidak. Anakanak kelas dua jarang menghawatirkan tulisan mereka, sebab mereka memberikan semua perhatian untuk menikmati aktivitas menulis dan bukannya mencari reaksi pembaca atau kesalahan ejaan. Sebaliknya bagi anak-anak kelas dua pengesahan dan penerimaan sangatlah penting. Suatu contoh, jika guru memuji cerita seorang siswa tentang binatang kesayangannnya, siswa 
yang lain mungkin akan memilih cerita yang mirip tentang binatang dengan harapan guru akan memuji pekerjaan mereka. Dengan demikian, pengakuan terhadap kemampuan diri mulai terlihat di kelas dua.

Penelitian tindakan kelas ini dilakukan untuk menggali masalah dari kenyataan-kenyataan yang terdapat di lingkungan pendidikan, yaitu permasalahan yang dihadapi pada saat proses belajar mengajar. Dalam melaksanakan pembelajaran, guru mendapatkan hasil belajar yang kurang memuaskan di kelas. Melihat kenyataan tersebut apalagi didukung dengan penelitian yang dilakukan, maka peneliti melakukan observasi dan wawancara untuk mengetahui apa penyebab munculnya keluhan para guru tersebut. Kegiatan observasi yang dilakukan tidak lain untuk mengetahui permasalahan yang muncul baik itu dari segi pembelajaran, kinerja guru, aktivitas siswa dan hasil belajar.

Dalam observasi dan wawancara yang dilakukan, ditemukan permasalahan yang terjadi di kelas khususnya dalam pembelajaran Bahasa Indonesia yang difokuskan pada keterampilan menulis karangan sederhana atau cerita dengan menggunakan ejaan di SDN Mojolangu 3 Kota Malang. Temuan di atas selanjutnya akan dijelaskan sebagai data awal dalam melakukan penelitian yang nantinya akan dibandingkan dengan data akhir setelah dilakukannya tindakan dalam menyelesaikan masalah.

Bedasarkan hasil observasi peneliti didapatkan bahwa siswa Kelas II SDN Mojolangu 3 mengalami kesulitan dalam pembelajaran menulis khususnya menulis karangan sederhana atau cerita. Siswa masih sulit dalam penggunaan ejaan. Kegiatan pembelajaran di sekolah menunjukkan kegiatan pembelajaran menulis belum optimal. Hal tersebut ditunjukkan kurang mampunya siswa dalam mengemukakan pendapat dan gagasannya secara kreatif serta kurang mampu mendapatkan dan mengumpulkan informasi yang aktual sebagai bahan tulisan. Penyebab ketidak optimalan tersebut antara lain dikarenakan metode yang digunakan belum dikolaborasikan dengan pembelajaran yang menarik, untuk penyampaian materi sudah baik namun hanya dibutuhkan metode pemelajaran yang bervariasi agar siswa tidak mengalami kejenuhan dalam belajar.

Pola pembelajaran menulis yang dikembangkan sangat berstruktur dan mekanis, mulai dari penentuan topik, penyeragaman kerangka tidaklah selamanya bijaksana. Dengan adanya penyeragaman topik, penyeragaman pola, menyebabkan kreativitas siswa menjadi kurang berkembang. Peserta didik merasa materi tersebut asing karena informasi awal tentang topik yang akan ditulis tersebut kurang memadai. Akibatnya, pembelajaran menulis karangan sederhana atau cerita tidak menarik, tidak alamiah, dan tidak bermakna. Siswa akan kehilangan gairah dalam mengikuti pembelajaran menulis sehingga keterampilan peserta didik dalam menulis khususnya dalam menulis karangan sederhana atau menulis cerita menjadi terhambat.

Tompkins (1994:105), menyatakan terlalu menuntut kesempurnaan hasil tulisan dari peserta didik justru dapat menghentikan kemauan siswa untuk menulis. Oleh karena itu peneliti merancang sebuah pembelajaran yang mampu memotivasi peserta didik selama mengikuti proses belajar mengajar. Salah satu alternatif dalam penelitian ini yaitu menerapkan metode "Permainan Dadu Ejaan".

\section{METODE PENELITIAN}

Sesuai dengan latar belakang di atas, maka metode penelitian ini menggunakan metode penelitian tindakan kelas. Penelitian Tindakan Kelas ini berlokasi di SDN MOJOLANGU 3. Penelitian ini dilakukan oleh guru kelas pada waktu mengajar di dalam kelas dan tujuannya untuk memperbaiki dan meningkatkan pembelajaran me- 
nulis karangan atau cerita sederhana dengan menggunakan metode permainan dadu ejaan.

Dalam penelitian tindakan kelas ini guru praktikan meneliti sendiri kegiatan yang dilakukannya di dalam kelas. Dengan melibatkan siswa, melalui tindakantindakan pembelajaran yang direncanakan, dilaksanakan, dan dievaluasikan. Penelitian ini dilakukan dengan berkolaborasi dengan guru kelas lain yang bertindak sebagai pengamat. Guru dan siswa sama-sama terlibat dalam proses pembelajaran, namun guru hanya sebagai mediator siswa yang harus aktif dan bertanggung jawab atas pembelajarannya.

Penelitian ini dilaksanakan dengan dua siklus yang masing-masing memiliki empat tahapan sebagai berikut.

1. Perencanaan

Dalam tahap ini guru mempersiapkan segala instrumen yang akan digunakan dalam penelitian antara lain; lembar pengamatan aktivitas guru dan siswa, rencana pembelajaran, bahan dan media pembelajaran, penyusunan soal dan angket respon siswa.

2. Implementasi

Pada tahap implementasi ini, kegiatan pembelajaran diawali dengan guru menyampaikan topik pembelajaran mengenai menulis karangan atau cerita sederhana, kemudian guru menyampaikan tujuan pembelajaran dan memberikan apersepsi selama sepuluh menit kepada siswa. Guru menunjukkan contoh karangan atau cerita sederhana kepada siswa. Guru dan siswa sama-sama terlibat dalam proses pembelajaran, namun guru hanya sebagai mediator, siswa yang harus aktif dan bertanggung jawab atas pembelajarannya.

3. Observasi

Dalam tahap observasi, peneliti mengamati perilaku dan perubahan sikap yang terjadi pada siswa setelah diterapkannya tindakan kelas dan dibantu oleh seorang pengamat yaitu teman sejawat. Pengamat mengamati proses pembelajaran sesuai dengan instrumen yang tersedia. Instrumen meliputi aktivitas guru dan siswa di kelas, dan hasil tes dan data respon siswa terhadap pembelajaran menulis karangan atau cerita sederhana dengan metode permainan dadu ejaan.

4. Refleksi

Pada tahap ini, guru mengkaji, melihat dan mempertimbagkan atas hasil implementasi. Tahap refleksi dilihat dari tahap implementasi dan observasi, melalui tahap ini dirancang tindakan yang akan diterapkan pada siklus berikutnya yaitu siklus I dan siklus II. Tiap siklus terjadilah tahap perencanaan - tindakan - observasi - refleksi.

Data yang digunakan dalam penelitian ini adalah sebagai berikut.

1) Data aktivitas guru dan siswa dalam proses pembelajaran menulis karangan atau cerita sederhana dengan metode permainan dadu ejaan.

2) Data hasil pembelajaran menulis karangan atau cerita dengan menggunakan metode permainan dadu ejaan yang sesuai dengan petunjuk tugas.

\section{Teknik Analisis Data}

1. Tes

Tes dilakukan setiap akhir pembelajaran. Tes tersebut merupakan lembar kerja siswa dalam menulis karangan atau cerita di setiap siklusnya. Tes diberikan untuk mendapatkan data tentang hasil belajar siswa ditinjau dari ketuntasan belajar siswa.

$$
\mathrm{T}=\stackrel{x}{N} \text {------X 100\% }
$$

Keterangan:

$\mathrm{T}=$ ketuntasan

$\mathrm{x}=$ jumlah siswa yang mendapat nilai.

$\mathrm{N}=$ jumlah siswa keseluruhan

2. Angket 
Angket diberikan kepada siswa di setiap akhir pembelajaran menulis karangan atau cerita dengan metode permainan dadu ejaan. Dari respon siswa peneliti dapat menentukan perbaikan menulis karangan atau cerita dengan metode permainan dadu ejaan pada proses pembelajaran berikutnya. Data dari angket tentang respon siswa di analisis dengan menggunakan persentase (\%), yaitu jumlah siswa yang memberi respon dibagi jumlah siswa keseluruhan dikalikan 100\%.

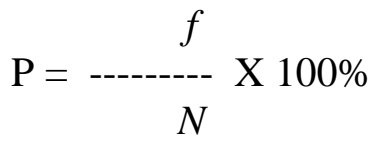

Keterangan:

$\mathrm{P}=$ persentase respon siswa

$\mathrm{f}=$ frekuensi kejadian yang muncul

$\mathrm{N}=$ jumlah siswa keseluruhan

3. Dokumentasi

Dokumentasi diperoleh dari hasil kuis siswa, LKS, lembar observasi, lembar wawancara, catatan lapangan, daftar kelompok siswa, dan foto-foto selama proses pembelajaran. Berdasarkan KKM (Kriteria Ketuntasan Minimal) mata pelajaran Bahasa Indonesia kelas II SDN Mojolangu 3, maka siswa dikatakan lulus pada materi tersebut ketika memperoleh nilai 75 ke atas dan siswa dinyatakan tidak lulus ketika memperoleh nilai di bawah 75 .

\section{HASIL DAN PEMBAHASAN}

Data penelitian yang diperoleh dalam penelitian ini adalah data dari lembar observasi berupa pengamatan aktivitas guru dan siswa pada setiap siklus pembelajaran, hasil tes kemampuan siswa pada setiap siklus, dan data respon siswa terhadap proses pembelajaran pada setiap siklus. Data hasil pengamatan terhadap aktivitas guru pada pertemuan pertama yang merupakan siklus pertama selama kegiatan belajar mengajar berlangsung dinyatakan dalam persentase. Data hasil pengamatan aktivitas guru pada siklus pertama tersebut ada pada tabel di bawah ini.
Tabel Data Aktivitas Guru dalam Pembelajaran Siklus 1

\begin{tabular}{|c|l|c|}
\hline No & Kategori Aktivitas Guru & Persentase \\
\hline 1. & Membuka pelajaran & $4,88 \%$ \\
2. & Menyampaikan tujuan & $7,32 \%$ \\
3. & pembelajaran & $7,32 \%$ \\
4. & Memberi motivasi pada & $14,63 \%$ \\
5. & siswa & $4,88 \%$ \\
6. & Menyampaikan materi & $9,76 \%$ \\
7. & pelajaran & $9,76 \%$ \\
8. & Membantu siswa & $19,51 \%$ \\
9. & menemukan masalah dan & $7,32 \%$ \\
10. & idenya sendiri & $7,32 \%$ \\
11. & Menggunakan media & $2,44 \%$ \\
12. & pembelajaran & $4,88 \%$ \\
& Menggali pengetahuan & \\
& dari siswa lewat bertanya & \\
& Memberikan informasi & \\
& sebanyak-banyaknya & \\
& kepada siswa & \\
& Memberikan kesempatan & \\
& untuk berdiskusi & \\
& Memberikan tugas & \\
& Memberi penghargaan & \\
& pada siswa & \\
& Membantu siswa & \\
\hline
\end{tabular}

Tabel Data Hasil Belajar Siswa dalam

\begin{tabular}{|c|c|c|c|c|c|c|c|c|c|}
\hline \multicolumn{10}{|c|}{ Pembelajaran } \\
\hline \multirow{3}{*}{ No } & \multirow{3}{*}{$\begin{array}{l}\text { Nam } \\
\text { a }\end{array}$} & & ek y & ig di & & \multirow{3}{*}{$\begin{array}{c}\text { JM } \\
\text { L } \\
\text { sko } \\
\text { r }\end{array}$} & \multirow{3}{*}{$\begin{array}{c}\text { Nil } \\
\text { ai }\end{array}$} & \multirow{2}{*}{\multicolumn{2}{|c|}{$\begin{array}{l}\text { Tafsi } \\
\text { ran }\end{array}$}} \\
\hline & & $\begin{array}{l}\text { Pe } \\
\text { ny } \\
\text { us } \\
\text { un } \\
\text { an } \\
\text { Ka }\end{array}$ & $\begin{array}{l}\text { Pe } \\
\text { ng } \\
\text { gu } \\
\text { na } \\
\text { an } \\
\text { Hu }\end{array}$ & $\begin{array}{l}\text { Pe } \\
\text { ng } \\
\text { gu } \\
\text { na } \\
\text { an } \\
\text { Ta }\end{array}$ & $\begin{array}{c}\text { Ke } \\
\text { ra } \\
\text { pih } \\
\text { an } \\
\text { tuli } \\
\text { san }\end{array}$ & & & & \\
\hline & & $\begin{array}{l}\text { Sk } \\
\text { or } \\
25\end{array}$ & $\begin{array}{l}\text { Sk } \\
\text { or } \\
25\end{array}$ & $\begin{array}{l}\text { Sk } \\
\text { or } \\
25\end{array}$ & $\begin{array}{l}\text { Sk } \\
\text { or } \\
25\end{array}$ & & & $\mathbf{L}$ & $\begin{array}{l}\mathbf{T} \\
\mathbf{L}\end{array}$ \\
\hline 1 & $\begin{array}{l}\text { A D } \\
\text { L }\end{array}$ & 20 & 20 & 20 & 15 & 75 & 75 & $\mathrm{~L}$ & \\
\hline 2 & $\begin{array}{l}\mathrm{AM} \\
\mathrm{R}\end{array}$ & 17 & 18 & 15 & 15 & 65 & 65 & & $\begin{array}{l}\mathrm{T} \\
\mathrm{L}\end{array}$ \\
\hline 3 & $\begin{array}{l}\text { A V } \\
\text { T O }\end{array}$ & 20 & 20 & 20 & 20 & 80 & 80 & $\mathrm{~L}$ & \\
\hline 4 & $\begin{array}{l}\text { A M } \\
\text { L A }\end{array}$ & 20 & 18 & 18 & 17 & 80 & 80 & $\mathrm{~L}$ & \\
\hline 5 & $\begin{array}{l}\mathrm{AN} \\
\mathrm{D} \mathrm{K}\end{array}$ & 18 & 17 & 17 & 18 & 80 & 80 & $\mathrm{~L}$ & \\
\hline 6 & $\begin{array}{l}\text { A N } \\
\text { D N }\end{array}$ & 16 & 16 & 15 & 17 & 75 & 75 & $\mathrm{~L}$ & \\
\hline 7 & $\begin{array}{l}\text { A N } \\
\text { G L }\end{array}$ & 18 & 16 & 18 & 16 & 85 & 85 & $\mathrm{~L}$ & \\
\hline
\end{tabular}


Karangan Sederhana Bagi Siswa Kelas 2 Semester II SDN Mojolangu 3 Kota Malang

Tahun 2012-2013

\begin{tabular}{|c|c|c|c|c|c|c|c|c|c|}
\hline \multirow{3}{*}{ No } & \multirow{3}{*}{$\begin{array}{l}\text { Nam } \\
\text { a }\end{array}$} & \multicolumn{4}{|c|}{ Aspek yang dinilai } & \multirow{3}{*}{$\begin{array}{c}\text { JM } \\
\text { L } \\
\text { sko } \\
\text { r }\end{array}$} & \multirow{3}{*}{$\begin{array}{c}\text { Nil } \\
\text { ai }\end{array}$} & \multirow{2}{*}{\multicolumn{2}{|c|}{$\begin{array}{c}\text { Tafsi } \\
\text { ran }\end{array}$}} \\
\hline & & $\begin{array}{l}\text { Pe } \\
\text { ny } \\
\text { us } \\
\text { un } \\
\text { an } \\
\text { Ka } \\
\text { lim }\end{array}$ & $\begin{array}{l}\text { Pe } \\
\text { ng } \\
\text { gu } \\
\text { na } \\
\text { an } \\
\text { Hu } \\
\text { ruf }\end{array}$ & $\begin{array}{l}\text { Pe } \\
\text { ng } \\
\text { gu } \\
\text { na } \\
\text { an } \\
\text { Ta } \\
\text { nd }\end{array}$ & $\begin{array}{c}\text { Ke } \\
\text { ra } \\
\text { pih } \\
\text { an } \\
\text { tuli } \\
\text { san }\end{array}$ & & & & \\
\hline & & $\begin{array}{c}\text { Sk } \\
\text { or } \\
25\end{array}$ & $\begin{array}{c}\text { Sk } \\
\text { or } \\
25\end{array}$ & $\begin{array}{l}\text { Sk } \\
\text { or } \\
25\end{array}$ & $\begin{array}{l}\text { Sk } \\
\text { or } \\
25\end{array}$ & & & $\mathbf{L}$ & $\begin{array}{l}\text { T } \\
\mathbf{L}\end{array}$ \\
\hline & A & & & & & & & & \\
\hline 8 & $\begin{array}{l}\text { A U } \\
\text { L I A }\end{array}$ & 21 & 20 & 20 & 20 & 90 & 90 & $\mathrm{~L}$ & \\
\hline 9 & $\begin{array}{l}\text { A X } \\
\text { L } \\
\end{array}$ & 23 & 22 & 21 & 21 & 90 & 90 & $\mathrm{~L}$ & \\
\hline 10 & D F A & 22 & 22 & 21 & 21 & 75 & 75 & $\mathrm{~L}$ & \\
\hline 11 & D N I & 17 & 14 & 13 & 14 & 80 & 80 & $\mathrm{~L}$ & \\
\hline 12 & $\begin{array}{l}\text { D W } \\
\text { P T }\end{array}$ & 12 & 13 & 14 & 11 & 40 & 40 & & $\begin{array}{l}\mathrm{T} \\
\mathrm{L}\end{array}$ \\
\hline 13 & E V & 13 & 17 & 16 & 14 & 78 & 78 & $\mathrm{~L}$ & \\
\hline 14 & $\begin{array}{l}\text { F N I } \\
\text { A }\end{array}$ & 21 & 18 & 22 & 19 & 70 & 70 & & $\begin{array}{l}\mathrm{T} \\
\mathrm{L}\end{array}$ \\
\hline 15 & F R L & 15 & 15 & 15 & 15 & 75 & 75 & $\mathrm{~L}$ & \\
\hline 16 & $\begin{array}{l}\text { F C K } \\
\text { Y }\end{array}$ & 17 & 15 & 16 & 17 & 50 & 50 & & $\begin{array}{l}\mathrm{T} \\
\mathrm{L}\end{array}$ \\
\hline 17 & $\begin{array}{l}\text { F R } \\
\text { M N }\end{array}$ & 17 & 15 & 17 & 16 & 75 & 75 & $\mathrm{~L}$ & \\
\hline 18 & FD O & 12 & 12 & 14 & 12 & 70 & 70 & & $\begin{array}{l}\mathrm{T} \\
\mathrm{L}\end{array}$ \\
\hline 19 & $\begin{array}{l}\text { K HR } \\
\text { S M }\end{array}$ & 20 & 19 & 20 & 20 & 75 & 75 & $\mathrm{~L}$ & \\
\hline 20 & $\begin{array}{l}\text { K H } \\
\text { N S }\end{array}$ & 20 & 20 & 19 & 18 & 90 & 90 & $\mathrm{~L}$ & \\
\hline 21 & $\begin{array}{l}\text { M H } \\
\text { R C }\end{array}$ & 19 & 17 & 19 & 19 & 80 & 80 & $\mathrm{~L}$ & \\
\hline 22 & $\begin{array}{l}\text { M V } \\
\text { A H } \\
\text { N }\end{array}$ & 21 & 19 & 20 & 20 & 70 & 70 & & $\begin{array}{l}\mathrm{T} \\
\mathrm{L}\end{array}$ \\
\hline 23 & $\begin{array}{l}\text { M R } \\
\mathrm{O}\end{array}$ & 17 & 19 & 18 & 17 & 55 & 55 & & $\begin{array}{l}\mathrm{T} \\
\mathrm{L} \\
\end{array}$ \\
\hline 24 & $\begin{array}{l}\text { M C } \\
\text { HR L }\end{array}$ & 17 & 16 & 17 & 17 & 75 & 75 & $\mathrm{~L}$ & \\
\hline 25 & $\begin{array}{l}\text { M K } \\
\text { H D } \\
\text { R }\end{array}$ & 20 & 18 & 20 & 16 & 75 & 75 & $\mathrm{~L}$ & \\
\hline 26 & $\begin{array}{l}\text { M K } \\
\text { L S }\end{array}$ & 18 & 18 & 17 & 17 & 70 & 70 & & $\begin{array}{l}\mathrm{T} \\
\mathrm{L}\end{array}$ \\
\hline 27 & $\begin{array}{l}\text { P N D } \\
\mathrm{U}\end{array}$ & 20 & 17 & 16 & 17 & 75 & 75 & $\mathrm{~L}$ & \\
\hline 28 & $\begin{array}{l}\text { R I S } \\
\mathrm{Y}\end{array}$ & 17 & 15 & 18 & 20 & 60 & 60 & & $\begin{array}{l}\mathrm{T} \\
\mathrm{L}\end{array}$ \\
\hline 29 & $\begin{array}{l}\text { R D } \\
\text { H O }\end{array}$ & 19 & 20 & 17 & 16 & 80 & 80 & $\mathrm{~L}$ & \\
\hline 30 & $\begin{array}{l}\text { R Z K } \\
\mathrm{Y}\end{array}$ & 20 & 18 & 16 & 17 & 80 & 80 & $\mathrm{~L}$ & \\
\hline 31 & $\begin{array}{l}\text { S L } \\
\text { M A }\end{array}$ & 19 & 19 & 18 & 19 & 85 & 85 & $\mathrm{~L}$ & \\
\hline 32 & $\begin{array}{l}\text { S HR } \\
\mathrm{H}\end{array}$ & 23 & 22 & 20 & 20 & 90 & 90 & $\mathrm{~L}$ & \\
\hline 33 & $\begin{array}{l}\text { S H N } \\
\text { A }\end{array}$ & 12 & 13 & 12 & 15 & 70 & 70 & & $\begin{array}{l}\mathrm{T} \\
\mathrm{L}\end{array}$ \\
\hline 34 & $\begin{array}{l}\text { S T V } \\
\text { N I }\end{array}$ & 18 & 18 & 19 & 19 & 85 & 85 & $\mathrm{~L}$ & \\
\hline 35 & $\begin{array}{l}\text { V A } \\
\mathrm{N}\end{array}$ & 17 & 16 & 17 & 15 & 80 & 80 & $\mathrm{~L}$ & \\
\hline 36 & $\begin{array}{l}\text { W A } \\
\text { G }\end{array}$ & 14 & 15 & 15 & 16 & 40 & 40 & & $\begin{array}{l}\mathrm{T} \\
\mathrm{L}\end{array}$ \\
\hline 37 & $\begin{array}{l}\text { W N } \\
\text { D A }\end{array}$ & 19 & 18 & 20 & 19 & 75 & 75 & $\mathrm{~L}$ & \\
\hline 38 & $\begin{array}{l}\text { W L } \\
\text { D A }\end{array}$ & 10 & 10 & 10 & 10 & 60 & 60 & & $\begin{array}{l}\mathrm{T} \\
\mathrm{L}\end{array}$ \\
\hline 39 & $\begin{array}{l}\text { W N } \\
\text { D }\end{array}$ & 20 & 18 & 20 & 20 & 75 & 75 & $\mathrm{~L}$ & \\
\hline 40 & M Z & 14 & 14 & 12 & 11 & 75 & 75 & $\mathrm{~L}$ & \\
\hline
\end{tabular}

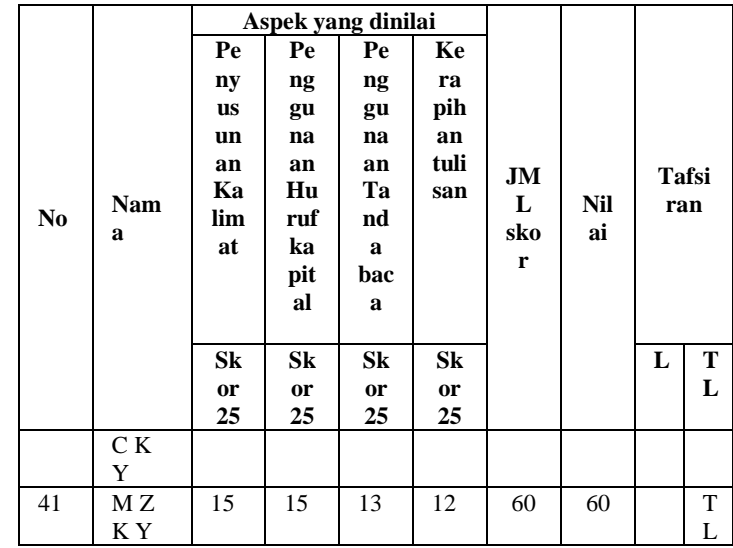

Kriteria setiap poin :

A. Kesesuaian dalam menyusun kalimat : maksimal 25

B. Penggunaan huruf kapital : maksimal 25

C. Penggunaan tanda baca : maksimal 25

D. Kerapihan tulisan : maksimal 25

Skor maksimum : 100

Nilai $=\underline{\text { Skor yang diperoleh }} \times 100$

Skor maksimum

Perecanaan penelitian yang dilakukan pada siklus kedua terdiri atas menyediakan rencana pembelajaran, lembar pengamatan aktivitas guru dan siswa, menyiapkan media pembelajaran, dan soal tes.

\section{Tabel Data Aktivitas Guru dalam} Pembelajaran Siklus 2

\begin{tabular}{|c|l|c|}
\hline No & $\begin{array}{c}\text { Kategori Aktivitas } \\
\text { Guru }\end{array}$ & Persentase \\
\hline 1 & Membuka pelajaran & $5,77 \%$ \\
2 & Menyampaikan tujuan & $5,77 \%$ \\
3 & pembelajaran & $15,38 \%$ \\
4 & Memberi motivasi & $5,77 \%$ \\
5 & pada siswa & $15,38 \%$ \\
6 & Menyampaikan materi & $7,69 \%$ \\
7 & pelajaran & $13,46 \%$ \\
8 & Membantu siswa & $9,62 \%$ \\
9 & menemukan masalah & $1,9 \%$ \\
10 & dan idenya sendiri & $9,62 \%$ \\
11 & Menggunakan media & $3,85 \%$ \\
12 & pembelajaran & $5,77 \%$ \\
& Menggali & \\
& pengetahuan dari & \\
\hline
\end{tabular}




\begin{tabular}{|l|l|}
\hline Siswa lewat bertanya & \\
Memberikan & \\
informasi sebanyak- & \\
banyaknya kepada & \\
siswa & \\
Memberikan & \\
kesempatan untuk & \\
berdiskusi & \\
Memberikan tugas & \\
Memberi penghargaan & \\
pada siswa & \\
Membantu siswa & \\
melakukan refleksi & \\
pembelajaran & \\
\hline
\end{tabular}

\section{Tabel Data Hasil Belajar Siswa dalam Pembelajaran}

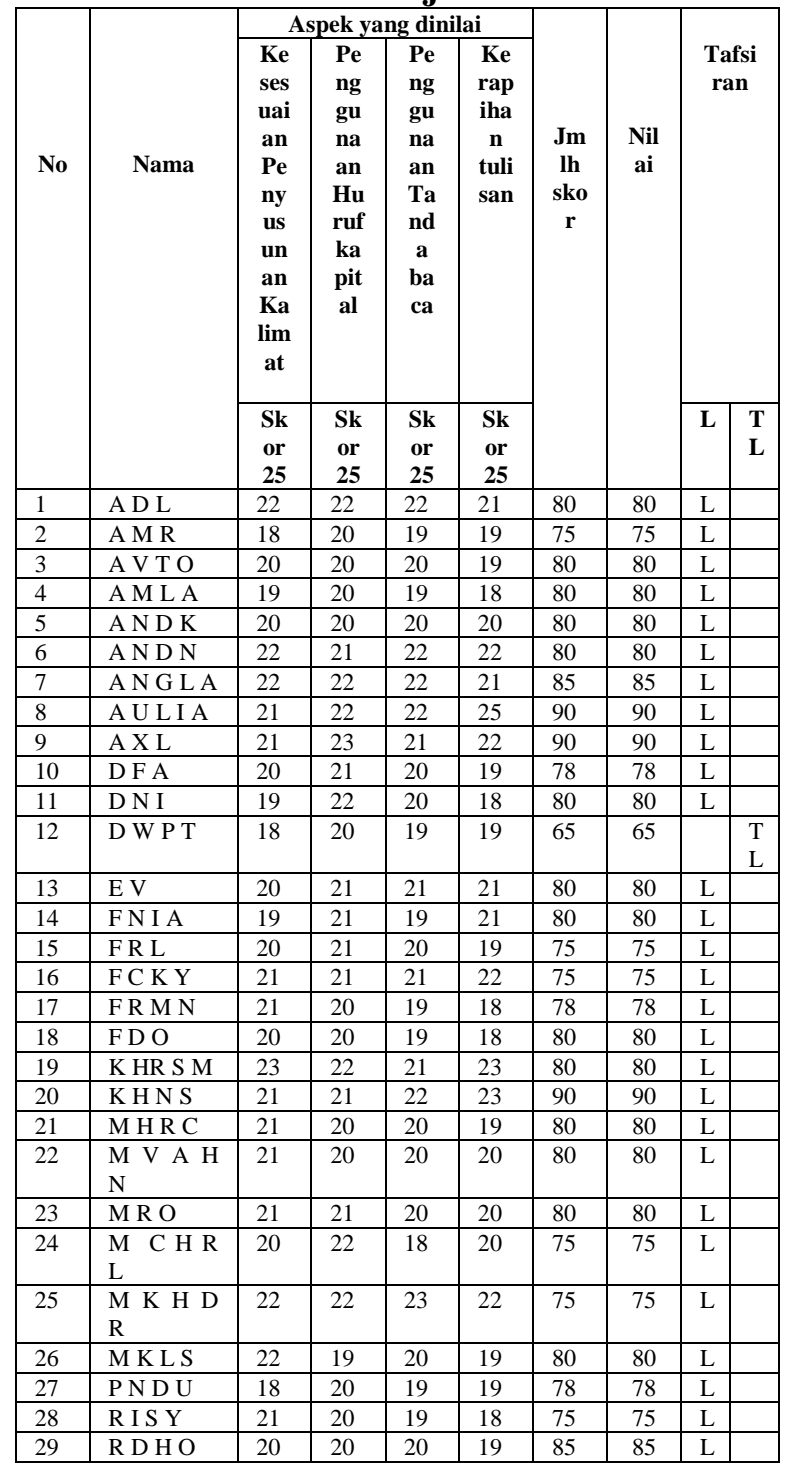

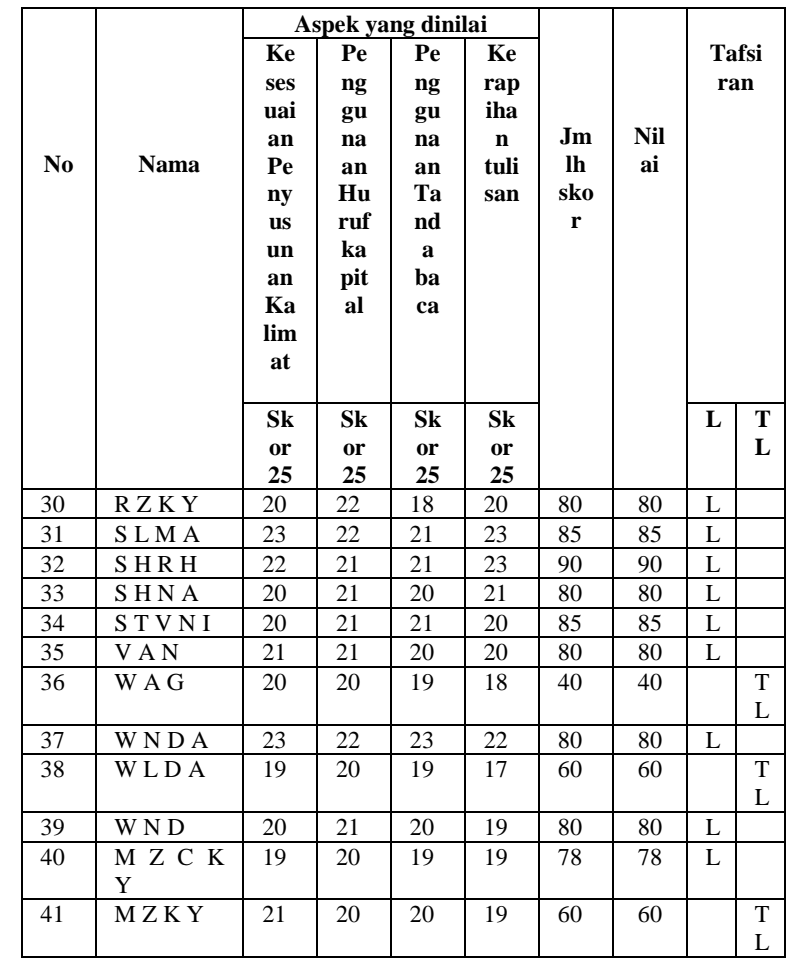

Kriteria setiap poin :

A. Kesesuaian dalam menyusun kalimat : maksimal 25

B. Penggunaan huruf kapital : maksimal 25

C. Penggunaan tanda baca : maksimal 25

D. Kerapihan tulisan : maksimal 25

Skor maksimum : 100

$$
\text { Nilai }=\frac{\text { Skor yang diperoleh }}{\text { Skor maksimum }} \times 100
$$

Dari hasil pembelajaran pada siklus 1 dan siklus 2 dapat disimpulkan bahwa dengan menerapkan metode permainan dadu ejaan dalam pembelajaran menulis karangan sederhana siswa Kelas 2 SDN Mojolangu 3 dari siklus I sampai dengan siklus II mengalami peningkatan.

Siswa memberikan respon yang sangat baik untuk media pembelajaran yang digunakan guru sehingga dapat membantu siswa memahami materi pelajaran. Siswa berpendapat cukup baik tentang materi yang diajarkan selama pembelajaran. Dengan tingkat pemahaman yang dimiliki siswa membuat siswa aktif dalam me- 
ngerjakan tugas sehingga siswa juga berpendapat bahwa siswa tidak merasa kesulitan dalam menulis karangan sederhana dengan metode permainan dadu ejaan.

Siswa sangat senang dengan pembelajaran menulis karangan sederhana dengan menggunakan metode permainan dadu ejaan. Hal ini dapat dilihat dengan adanya peningkatan nilai dan respon siswa yang selalu antusias dalam mengikuti pembelajaran serupa yaitu menulis karangan sederhana dengan menggunakan metode permainan dadu ejaan.

\section{KESIMPULAN}

Berdasarkan Penelitian tindakan kelas yang telah dilaksanakan untuk peningkatan keterampilan menulis karangan sederhana dengan metode permainan dadu ejaan siswa Kelas II SDN Mojolangu 3 Kota Malang tahun pelajaran 2012-2013 menghasilkan kesimpulan berikut bahwa:

1. Penerapan permainan dadu ejaan dapat meningkatkan hasil belajar siswa pada pelajaran bahasa Indonesia kelas II di SDN Mojolangu 3 Kota Malang

2. Penerapan permainan dadu ejaan dapat meningkatkan respon siswa pada pelajaran bahasa Indonesia kelas II di SDN Mojolangu 3 Kota Malang.

\section{SARAN}

Saran yang dapat diberikan pada penelitian ini menurut temuan, pembahasan dan kesimpulan adalah untuk meningkatkan hasil belajar siswa memerlukan beberapa media yang mendukung. Dengan adanya media tersebut disarankan kepada guru mata pelajaran agar lebih memperhatikan kualitas media pembelajaran yang diberikan yang harus disesuaikan dengan kondisi siswa agar mampu menumbuhkan aktivitas siswa secara maksimal. Dengan permainan dadu ejaan dapat membantu kesulitan bel- ajar dan mampu memberikan peningkatan terhadap hasil belajar dan respon siswa. Oleh karena itu pada pihak sekolah khususnya pada mata pelajaran bahasa Indonesia. 